\title{
Serum 25-Hydroxyvitamin D were associated with higher risk of both albuminuria and impaired GFR incidence: a cohort study based on CLHLS study
}

Miao Liu* ${ }^{*}$ (D), Jianhua Wang ${ }^{\dagger}$ and Yao He

\begin{abstract}
Background: This study aimed to examine the relationship between 25-hyfromxyvitamin D (25OHD) and chronic kidney disease (CKD) incidence.

Methods: All the elderly who had participated both in the 2011-2012 survey and 2014 survey in the Chinese Longitudinal Healthy Longevity Survey (CLHLS), and have biomarker data were included in the analysis. We studied those without CKD with complete data at 2011-2012 waves. Serum 25-Hydroxyvitamin D was assessed at baseline. Cox proportional risk model was used to evaluate associations between serum 25-Hydroxyvitamin D and CKD (including both albuminuria and impaired eGFR) incidence after adjusted for potential confounding..

Results: During the follow-up years, 255 incident cases of CKD were diagnosed. Those who developed CKD had

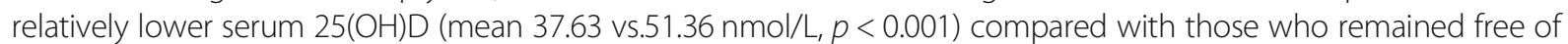
CKD. Each $1 \mathrm{nmol} / \mathrm{L}$ increase in 25(OH)D was associated with 3.4\% reduced risk of CKD (HR=0.966, 95\%Cl: 0.959-0.973) after adjusted for related covariates. The HRs of each $1 \mathrm{nmol} / \mathrm{L}$ increase in $25(\mathrm{OH}) \mathrm{D}$ for albuminuria and impaired eGFR were 0.952 (95\%Cl: $0.941-0.963$ ) and $0.975(95 \% \mathrm{Cl}$ : 0.966-0.983) respectively. When use the classifications (sufficiency, insufficiency, deficiency) or quintiles of baseline $25(\mathrm{OH}) \mathrm{D}$ levels in the Cox model, the corresponding HRs showed an increasing trend along with the decrease of baseline $25(\mathrm{OH}) \mathrm{D}$ levels ( $p$ for trend $<0.001$ ).
\end{abstract}

Conclusions: Higher 25(OH)D levels were inversely and independently associated with CKD incidence among Chinese elderly. The trend for the observed linear relationship b was most pronounced among the lowest quintile.

Keywords: Chronic kidney disease, Impaired glomerular filtration rate, Albuminuria 25-Hydroxyvitamin D, Cohort

\section{Background}

Vitamin D is a pro-steroid hormone, and first hydroxylated to $25(\mathrm{OH}) \mathrm{D}$ in the liver, and further hydroxylated to $1,25(\mathrm{OH})_{2} \mathrm{D}$ in the renal proximal convoluted tubules. Then $1,25(\mathrm{OH})_{2} \mathrm{D}$ were combined with receptors in the target tissues to play its biological roles [1]. The widespread recognition of vitamin $\mathrm{D}$ was its regulation of calcium and phosphorus metabolism. In recent years, it has been found that vitamin $\mathrm{D}$ has a wide range of metabolic and cell

\footnotetext{
* Correspondence: liumiaolmbxb@163.com

${ }^{\dagger}$ Miao Liu and Jianhua Wang contributed equally to this work.

Institute of Geriatrics, Beijing Key Laboratory of Aging and Geriatrics, National clinical research center for geriatrics diseases, State Key Laboratory of Kidney Diseases, Chinese PLA General Hospital, 28 Fuxing Road, Beijing 100853, China
}

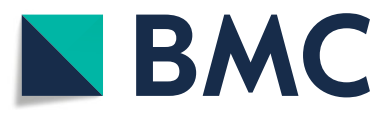

(c) The Author(s). 2019 Open Access This article is distributed under the terms of the Creative Commons Attribution 4.0 International License (http://creativecommons.org/licenses/by/4.0/), which permits unrestricted use, distribution, and reproduction in any medium, provided you give appropriate credit to the original author(s) and the source, provide a link to the Creative Commons license, and indicate if changes were made. The Creative Commons Public Domain Dedication waiver (http://creativecommons.org/publicdomain/zero/1.0/) applies to the data made available in this article, unless otherwise stated.

regulatory functions [2]. It has been a recent research hotspot about the role of vitamin $\mathrm{D}$ in tumor, endocrine, immunity, cardiovascular and kidney diseases [3-5]. It plays an important role in inhibiting cell proliferation, inducing cell apoptosis and differentiation, regulating immune function, protecting organ function and gene protection by combining with vitamin D receptor [6].

Chronic kidney disease (CKD) is one of the most important diseases which affect about $10-15 \%$ of adults. Epidemiological data showed that the prevalence of CKD increase for the past 20 years $[7,8]$. Besides, compared with cardiovascular diseases and diabetes, people have not paid sufficient attention to CKD. Most of the patients went to the hospital when they had appeared clinical symptoms or 
were already in the late stage, resulting in poor prognosis and huge disease burden [9]. Therefore, there is a series of researches focused on risk factors about CKD incidence. Recently, a series of studies showed that vitamin D and serum 25(OH)D deficiency had emerged as one important independent risk factor for CKD [4, 10, 11]. Animal and cell cultural experimental data showed that vitamin D inhibits renin transcription, reduces circulating angiotensin II level, prevents phagocyte loss and glomerulosclerosis, and reduces urinary albumin excretion. And in human studies, lower vitamin D levels were independently associated with higher risk of albuminuria and CKD. However, most of the studies about vitamin D and CKD were cross-sectional studies, and there were lack of evidence based on prospective studies. In addition, the prevalence of vitamin D deficiency varies by gender, season of the year, sunlight exposure and a number of other environmental factors and comorbidities [12]. Besides, most studies were of albuminuria, less were about the impaired estimated glomerular filtration (eGFR), which was also very important for CKD $[4,8,10,13]$. Accordingly, this study, which was based on data from two waves of the Chinese Longitudinal Healthy Longevity Survey (CLHLS) occurring from 2011 to 2012 to 2014 , aimed to examined weather lower 25(OH)D level was associated with both albuminuria and impaired eGFR based on a cohort design using Cox proportional risk model.

\section{Methods}

\section{Study population}

The data of this study was from CLHLS, a high-quality longitudinal survey based on Chinese elderly [14]. In CLHLS study, a multi-stage target random sampling method with unequal proportion was adopted in order to ensure enough samples for each age group. The sampling steps were as follows: (1) about $50 \%$ of the counties/districts were randomly selected from 22 provinces; (2) in these areas, all surviving centenarians who volunteered to participate in the survey were visited by households; (3) those aged 65-79 yrs., 80-89 yrs., and 90-99 yrs. were randomly selected according to the centenarian number according to the protocol. A face-to-face interview was conducted to collect basic demographic characteristics, lifestyle, disease history and family history. Since vitamin D was first measured in 2011/2012 wave, we used this as the baseline survey and the most recent 2014 wave as the follow up survey.

\section{Study sample}

There were 9765 participants in 2011/2012 wave of the CLSHL. However, the blood biochemical tests were carried out only in 8 special areas-"The longevity village of China". Excluding 7448 participants who didn't have physical examination, there were 2317 participants. Those who had lost to follow up $(n=822)$, baseline CKD or related kidney disease $(n=394)$, hepatobiliary disease $(n=23)$, cancer $(n$
$=8)$ were also excluded. The flow chart was presented in Fig. 1.

\section{Vitamin D}

All blood samples were centrifuged within $1 \mathrm{~h}$ after collection, and the centrifuged specimens were placed in $-20^{\circ}$ and transported to Beijing for uniform testing. Since $1,25(\mathrm{OH})_{2} \mathrm{D}$ were generated in renal proximal convoluted tubules, which were closely related with renal function, and $25(\mathrm{OH}) \mathrm{D}$ had relatively long half-life, so we used $25(\mathrm{OH}) \mathrm{D}$ as the suitable biomarker for assessing vitamin D deficiency or insufficiency, as most of epidemiological studies $[4,10]$. The optimal vitamin D status was defined as serum $25(\mathrm{OH}) \mathrm{D}$ concentrations exceeding $75 \mathrm{nmol} / \mathrm{L}$ by the Endocrine Society [15]. According to the definition of endocrine society, serum $25(\mathrm{OH}) \mathrm{D}$ levels were classified into three categories: sufficiency/optimal levels, more than $75 \mathrm{nmol} / \mathrm{L}$; insufficiency, $50-75 \mathrm{nmol} / \mathrm{L}$; deficiency, less than $50 \mathrm{nmol} / \mathrm{L}$. Also, for analysis, we divided $25(\mathrm{OH}) \mathrm{D}$ levels into quintiles: < $29.80 \mathrm{nmol} / \mathrm{L} ; 29.80-39.85 \mathrm{nmol} / \mathrm{L} ; 39.85-50.00$ $\mathrm{nmol} / \mathrm{L} ; 50.0-62.90 \mathrm{nmol} / \mathrm{L} ; \geq 62.90 \mathrm{nmol} / \mathrm{L}$.

\section{CKD}

Albuminuria was defined as a urine albumin-creatinine ratio $(\mathrm{ACR})>30 \mathrm{mg} / \mathrm{g}$. eGFR was calculated according to Chinese-modified CKD-EPI (cCKD-EPI) equation [16]. Impaired GFR was defined as eGFR $<60 \mathrm{ml} / \mathrm{min} /$ $1.73 \mathrm{~m}^{2}$. CKD was defined positive as either albuminuria or impaired GFR.

\section{Covariates}

A standardized structured questionnaire was used to collect information, including demographic and sociological characteristics, lifestyle and disease history. Current married was classified into 5 categories (1 married and living with spouse; 2 married but not living with spouse; 3 divorced; 4 widowed; 5 never married;) and those answered 1 or 2 were classified into "yes". Current smoking was classified into "yes" or "no" in the question "Do you smoke at the present time". Current alcohol drinking was classified into "yes" or "no" in the question "Do you drink alcohol at the present time". Current exercise was classified into "yes" or "no" in the question "Do you often participate in physical activities". Previous diseases were self-reported including hypertension, diabetes, heart disease, and stroke/cerebrovascular disease.

\section{Statistical analysis}

Data were expressed as mean \pm standard deviation (SD) for continuous variable and $\mathrm{n}(\%)$ for categorical variable. Baseline characteristics between those who had CKD incidence and those who didn't develop CKD during follow up period were compared using independent $t$ test for continuous 


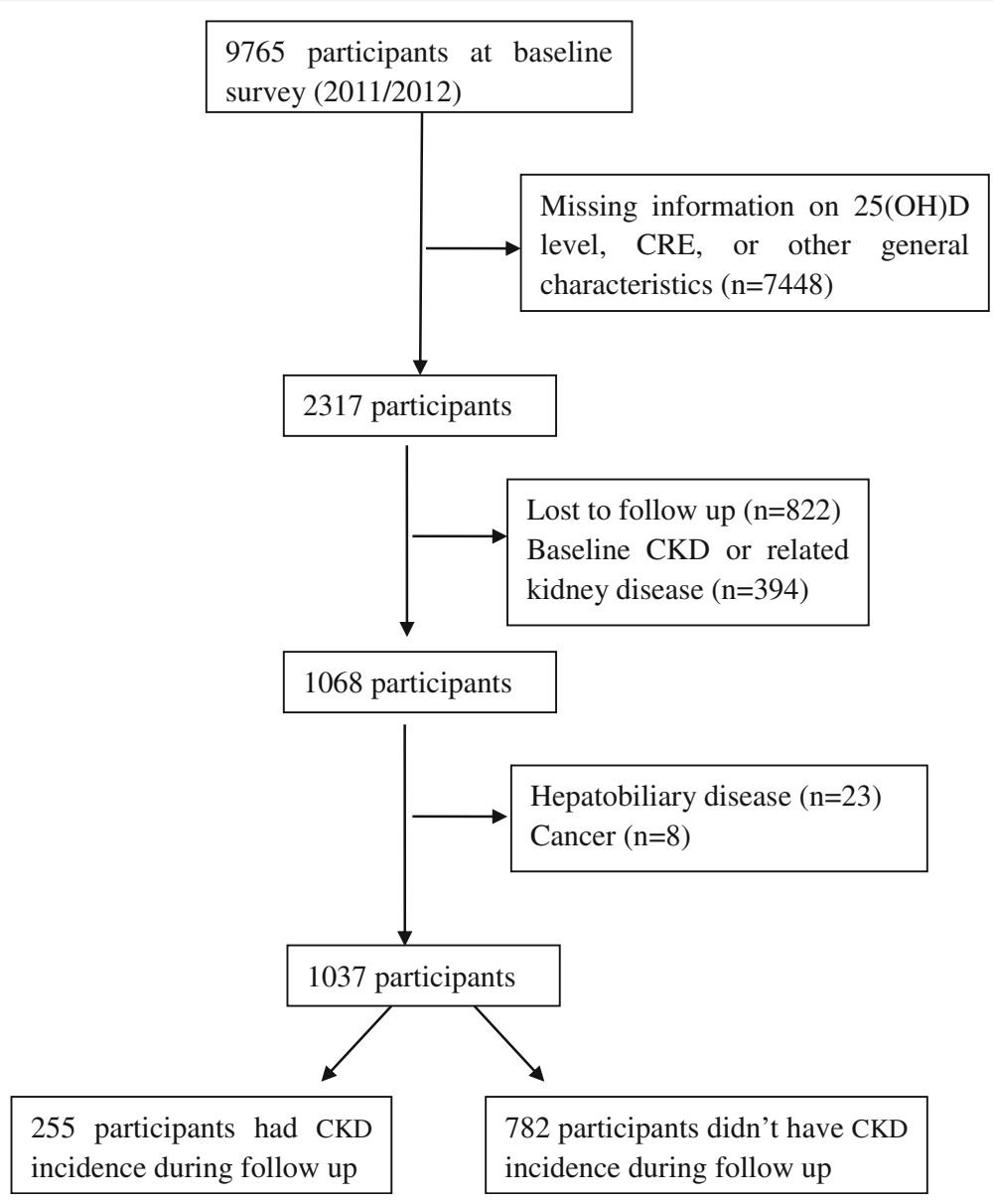

Fig. 1 Flow chart of inclusion of participants

variables and for categorical variables. Cox regression model was used to calculated the hazards ratio (HR) with 95\% CI and assess the relationships between CKD (including both albuminuria and impaired GFR) and 25(OH)D level (in three types, including continuous, categorical, and quintiles). Related covariates were adjusted in the model, including age, gender, marital status, current smoking, current alcohol drinking, current exercise, baseline body mass index (BMI), albumin(ALB), urea nitrogen(BUN), creatinine(CRE), uric acid(SUA), baseline prevalence of hypertension, diabetes, heart disease and stroke. All analysis was conducted using SPSS 19.0(SPSS Inc., Chicago, IL).

\section{Results}

The baseline characteristics of participants were shown in Table 1 and stratified by CKD new incident status. 1037 participants were included in the final analysis, and the mean age was $81.64 \pm 12.33$ years. The mean $25(\mathrm{OH}) \mathrm{D}$ was $47.98 \pm 22.00 \mathrm{nmol} / \mathrm{L}$. The percentages of male, married, current smoking, current alcohol drinking and current exercise were 68.9, 50.6, 19.9 and 17.2\% respectively. Compared with those who didn't have CKD incidence, those who had new CKD incident had relatively longer older age, higher SBP, TC, LDL-C, BUN, CRE, SUA levels, and lower HDL-C, ALB, and 25(OH)D levels $(p<0.05)$.

\section{Incidence of CKD according to baseline 25(OH)D level}

There were a total of 255 CKD cases during the 21,586 person-years. The total three years' incidence was $24.6 \%$ (95\%CI: $22.0-27.2 \%)$. For those who were of vitamin D deficiency (less than $50 \mathrm{nmol} / \mathrm{L}$ ) or insufficiency (50-75 $\mathrm{nmol} / \mathrm{L}$ ) at baseline, the CKD incidence was $32.7 \%$ (95\%CI: $29.0-36.4 \%)$ and $14.2 \%$ (95\%CI: $10.4-18.0 \%)$ respectively. For those who were of vitamin D sufficiency (more than $75 \mathrm{nmol} / \mathrm{L}$ ), the CKD incidence was $7.8 \%$ (95\%CI: 2.6-13.1\%). Besides, as we can see from Table 2, the CKD incidence decreased along with quintiles of baseline 25(OH)D level; the first quintile had the highest incidence $(44.4 \%)$ while the fifth had the lowest incidence (10.3\%). For albuminuria and impaired eGFR, the incidence showed a similar trend (Table 2). 
Table 1 Baseline characteristics of participants according to CKD status at follow-up survey

\begin{tabular}{|c|c|c|c|c|}
\hline \multirow[t]{2}{*}{ Characteristics } & \multicolumn{2}{|l|}{ CKD } & \multirow[t]{2}{*}{$P$} & \multirow[t]{2}{*}{ Total $(n=1037)$} \\
\hline & Yes $(n=255)$ & No $(n=782)$ & & \\
\hline \multicolumn{5}{|l|}{ mean $\pm S D$} \\
\hline Age (yrs) & $85.44 \pm 11.66$ & $80.40 \pm 12.30$ & $<0.001$ & $81.64 \pm 12.33$ \\
\hline Height (cm) & $154.81 \pm 10.45$ & $156.45 \pm 10.72$ & 0.031 & $156.04 \pm 10.70$ \\
\hline Weight (kg) & $51.57 \pm 12.17$ & $53.86 \pm 12.60$ & 0.011 & $53.30 \pm 12.53$ \\
\hline $\mathrm{BMI}\left(\mathrm{kg} / \mathrm{m}^{2}\right)$ & $21.36 \pm 3.90$ & $21.84 \pm 3.89$ & 0.087 & $21.72 \pm 3.89$ \\
\hline $\mathrm{SBP}(\mathrm{mmHg})$ & $146.50 \pm 24.49$ & $139.07 \pm 21.51$ & $<0.001$ & $139.28 \pm 21.64$ \\
\hline $\mathrm{DBP}(\mathrm{mmHg})$ & $81.45 \pm 12.53$ & $81.27 \pm 11.22$ & 0.827 & $81.32 \pm 11.55$ \\
\hline $\mathrm{TC}(\mathrm{mmol} / \mathrm{l})$ & $4.21 \pm 0.94$ & $4.42 \pm 0.95$ & 0.002 & $4.37 \pm 0.95$ \\
\hline $\mathrm{TG}(\mathrm{mmol} / \mathrm{l})$ & $1.01 \pm 0.59$ & $1.02 \pm 0.68$ & 0.861 & $1.02 \pm 0.66$ \\
\hline $\mathrm{HDL}-\mathrm{C}(\mathrm{mmol} / \mathrm{l})$ & $1.25 \pm 0.36$ & $1.32 \pm 0.36$ & 0.026 & $1.30 \pm 0.36$ \\
\hline LDL-C (mmol/l) & $2.48 \pm 0.77$ & $2.65 \pm 0.80$ & 0.008 & $2.61 \pm 0.79$ \\
\hline FPG (mmol/l) & $4.68 \pm 1.63$ & $4.59 \pm 2.10$ & 0.507 & $4.61 \pm 1.99$ \\
\hline ALB (g/L) & $40.23 \pm 5.04$ & $41.13 \pm 4.50$ & 0.002 & $41.03 \pm 4.65$ \\
\hline BUN (mmol/L) & $7.05 \pm 2.00$ & $6.55 \pm 1.72$ & $<0.001$ & $6.65 \pm 1.80$ \\
\hline CRE $(\mu \mathrm{mol} / \mathrm{L})$ & $89.79 \pm 28.29$ & $74.69 \pm 16.92$ & $<0.001$ & $78.40 \pm 21.53$ \\
\hline SUA ( $\mu \mathrm{mol} / \mathrm{L})$ & $322.26 \pm 96.22$ & $278.14 \pm 76.05$ & $<0.001$ & $289.00 \pm 8.36$ \\
\hline $25(\mathrm{OH}) \mathrm{D}(\mathrm{nmol} / \mathrm{L})$ & $37.63 \pm 16.40$ & $51.36 \pm 22.54$ & $<0.001$ & $47.98 \pm 22.00$ \\
\hline \multicolumn{5}{|l|}{$n(\%)$} \\
\hline Male & $124(48.6)$ & $383(49.0)$ & 0.923 & $507(48.9)$ \\
\hline Married & $159(62.4)$ & $366(46.8)$ & $<0.001$ & $525(50.6)$ \\
\hline Current smoking & $55(21.6)$ & $151(19.3)$ & 0.432 & $206(19.9)$ \\
\hline Illiteracy & 95 (37.3) & $366(46.8)$ & 0.008 & $461(44.5)$ \\
\hline Current alcohol drinking & $47(18.4)$ & $131(16.8)$ & 0.537 & $178(17.2)$ \\
\hline Current exercise & $31(12.2)$ & $127(16.2)$ & 0.115 & $158(15.2)$ \\
\hline Hypertension & $90(35.3)$ & $182(23.3)$ & $<0.001$ & $272(26.2)$ \\
\hline Diabetes & $22(8.6)$ & $52(6.6)$ & 0.287 & $74(7.1)$ \\
\hline Heart disease & $21(8.2)$ & $64(8.2)$ & 0.979 & $85(8.2)$ \\
\hline Stroke & $23(9.0)$ & $64(8.2)$ & 0.676 & $87(8.4)$ \\
\hline
\end{tabular}

Data are mean \pm SD for continuous values or $\%$ for category values

HRs and $95 \% \mathrm{Cl}$ of albuminuria, eGFR decrease and CKD incidence according to baseline 25(OH)D levels

Table 3 showed the HRs of baseline 25(OH)D levels for albuminuria, impaired eGFR and CKD incidence. In the Cox model, after adjusted for age, gender, marital status, current smoking, current alcohol drinking, current exercise, baseline BMI, ALB, BUN, CRE, SUA, baseline prevalence of hypertension, diabetes, heart disease and stroke in the model, the HRs of baseline 25(OH)D levels for albuminuria, impaired eGFR and CKD incidence were 0.952(95\%CI: 0.941-0.963), 0.975(95\%CI: 0.966-0.983), and 0.966(95\%CI: 0.959-0.973) respectively. When use the classifications (sufficiency, insufficiency, deficiency) or quintiles of baseline 25(OH)D levels in the Cox model, the corresponding HRs showed an increasing trend along with the decrease of baseline $25(\mathrm{OH}) \mathrm{D}$ levels ( $\mathrm{p}$ for trend < 0.001) (Table 3$)$.

\section{Discussion}

In this population based cohort study with a large sample, $25(\mathrm{OH}) \mathrm{D}$ deficiency was independently associated with CKD (including both albuminuria and impaired eGFR). The correlation between baseline $25(\mathrm{OH})$ D levels and CKD incidence was most pronounced among the lowest quintile. The trend for the observed linear relationship between baseline 25(OH)D levels and CKD incidence persisted with additional adjustment for related covariates.

The association between 25(OH)D deficiency and albuminuria incidence was demonstrated in previous studies. The results based on 10,732 adults from the AusDiab (Australian Diabetes, Obesity and Lifestyle) study showed that vitamin D deficiency (25(OHD) level $<50 \mathrm{nnol} / \mathrm{L}$ ) was significantly associated with albuminuria prevalence in the multivariate mode, and the OR was 1.54(95\%CI: 1.14-2.07) 


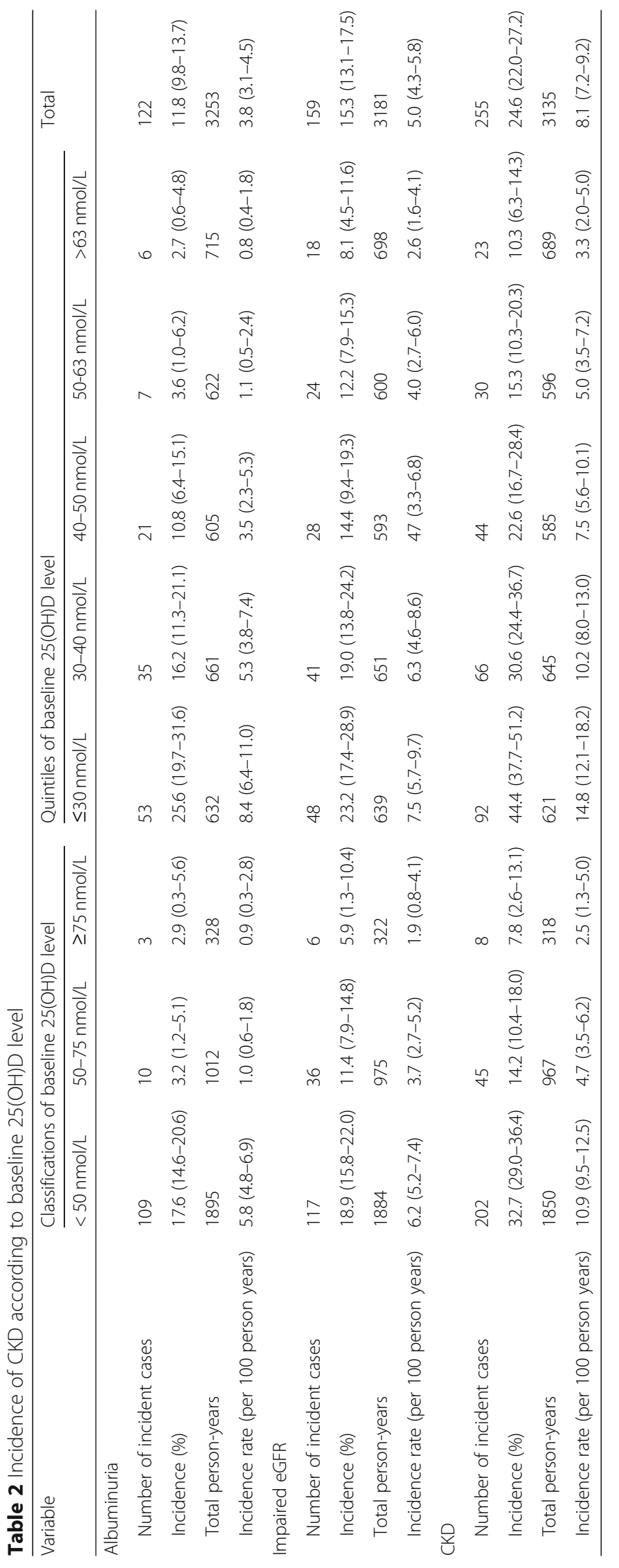


Table $3 \mathrm{HRs}$ and 95\% Cl of albuminuria, eGFR decrease and DKD incidence according to baseline 25(OH)D level

\begin{tabular}{|c|c|c|c|}
\hline & Variable type & $\mathrm{HR}^{*}(95 \% \mathrm{Cl})$ & $P$ \\
\hline \multirow[t]{11}{*}{ Albuminuria } & Continuous variable & $0.952(0.941-0.963)$ & $<0.001$ \\
\hline & Classifications & & $<0.001$ \\
\hline & $<50 \mathrm{nmol} / \mathrm{L}$ & $5.737(2.807-11.725)$ & \\
\hline & $50-75 \mathrm{nmol} / \mathrm{L}$ & $1.695(0.684-4.200)$ & \\
\hline & $\geq 75 \mathrm{nmol} / \mathrm{L}$ & 1.00 (Ref) & \\
\hline & Quintiles & & $<0.001$ \\
\hline & $\leq 30 \mathrm{nmol} / \mathrm{L}$ & $7.864(4.012-14.717)$ & \\
\hline & 30-40 nmol/L & $5.631(2.824-11.228)$ & \\
\hline & $40-50 \mathrm{nmol} / \mathrm{L}$ & $3.328(1.571-7.050)$ & \\
\hline & $50-63 \mathrm{nmol} / \mathrm{L}$ & $1.302(0.485-3.495)$ & \\
\hline & $>63 \mathrm{nmol} / \mathrm{L}$ & 1.00 (Ref) & \\
\hline \multirow[t]{11}{*}{ Impaired eGFR } & Continuous variable & $0.975(0.966-0.983)$ & $<0.001$ \\
\hline & Classifications & & $<0.001$ \\
\hline & $<50 \mathrm{nmol} / \mathrm{L}$ & $4.329(2.015-9.300)$ & \\
\hline & $50-75 \mathrm{nmol} / \mathrm{L}$ & $2.068(0.920-4.649)$ & \\
\hline & $\geq 75 \mathrm{nmol} / \mathrm{L}$ & 1.00 (Ref) & \\
\hline & Quintiles & & $<0.001$ \\
\hline & $\leq 30 \mathrm{nmol} / \mathrm{L}$ & 4.645 (2.808-7.684) & \\
\hline & 30-40 nmol/L & $4.120(2.460-6.900)$ & \\
\hline & $40-50 \mathrm{nmol} / \mathrm{L}$ & $2.750(1.598-4.732)$ & \\
\hline & $50-63 \mathrm{nmol} / \mathrm{L}$ & $2.010(1.156-3.495)$ & \\
\hline & $>63 \mathrm{nmol} / \mathrm{L}$ & 1.00 (Ref) & \\
\hline \multirow[t]{11}{*}{ CKD } & Continuous variable & 0.966 (0.959-0.973) & 0.003 \\
\hline & Classifications & & $<0.001$ \\
\hline & $<50 \mathrm{nmol} / \mathrm{L}$ & 4.667 (2.285-9.532) & \\
\hline & $50-75 \mathrm{nmol} / \mathrm{L}$ & $1.811(0.909-3.608)$ & \\
\hline & $\geq 75 \mathrm{nmol} / \mathrm{L}$ & 1.00 (Ref) & \\
\hline & Quintiles & & $<0.001$ \\
\hline & $\leq 30 \mathrm{nmol} / \mathrm{L}$ & $5.677(3.771-8.546)$ & \\
\hline & 30-40 nmol/L & $4.410(2.892-6.724)$ & \\
\hline & $40-50 \mathrm{nmol} / \mathrm{L}$ & $2.832(1.810-4.431)$ & \\
\hline & $50-63 \mathrm{nmol} / \mathrm{L}$ & $1.821(1.138-2.914)$ & \\
\hline & $>63 \mathrm{nmol} / \mathrm{L}$ & 1.00 (Ref) & \\
\hline
\end{tabular}

Adjusted for age, gender, marital status, illiteracy, current smoking, current alcohol drinking, current exercise, baseline BMI, ALB, BUN, CRE, SUA, baseline prevalence of hypertension, diabetes, heart disease and stroke

[4]. The results based on 15,068 adults from NHANES III (the Third National Health and Nutrition Examination Survey) showed that low $25(\mathrm{OH}) \mathrm{D}$ levels were associated with an increased prevalence of albuminuria in U.S. population [10]. The association was also demonstrated in a multicenter CKD cohort-Study of Early Evaluation of Kidney Disease, where low $25(\mathrm{OH}) \mathrm{D}$ levels were independently associated with albuminuria [17]. Our observations were in keeping with these findings, which added prospective evidence about the association between vitamin $\mathrm{D}$ and proteinuria.

Relationships between $25(\mathrm{OH})$ D levels and impaired GFR were inconclusive. There showed no significant associations in multivariate models in neither AusDiab study nor NHANESIII data $[4,10]$. Contrary to the results of cross-sectional study, the results of the cohort study demonstrated an association between $25(\mathrm{OH})$ D levels and GFR progression. In a small sample cohort consisted of stages 2-5 CKD patients, serum $25(\mathrm{OH})$ D predicted both time to death and end stage renal disease [18]. Another community-based cohort study also showed that lower 25(OH)D was associated with increased risk of GFR loss [12]. There were many reasons about this inconsistency for associations between cross-sectional studies and cohort studies. One may be attributable to the fact that vitamin D levels varies by people and were associated with season and sunlight [12]. Also,there existed another possible mechanism, some of CKD patients do not progress, [19]which indicated that $25(\mathrm{OH}) \mathrm{D}$ deficiency may be an indicator for distinguish from those who were at higher risk of progression and those who were not. However, there was no evidence about whether there was an association between 25(OH)D and impaired GFR incidence among normal participants who were free of CKD at baseline, and our results showed that lower $25(\mathrm{OH}) \mathrm{D}$ was associated with impaired GFR incidence based on cohort study. The results added evidence that $25(\mathrm{OH}) \mathrm{D}$ deficiency might be used as an indicator to distinguish from those who were at higher risk of impaired GFR incidence and those who were not.

The protective effect of vitamin D on CKD may be attributed to a set of mechanisms [20-22]. First, there was a series of evidence showed that the protective effect of vitamin D on renin can be treated by RAS and NK-kB. Vitamin D analogues would reduce the expression of renin and thus decrease the expression of angiotensin II, which is the key mediator of proteinuria and renal damage. Besides, low vitamin D levels were linked to higher expression of inflammatory parameters. Also, vitamin D levels might be associated with hypertension, impaired glucose metabolism, which was also correlated with CKD.

There were several strengths of this study. All the participants were recruited from a national level, and all interview and examination process was standardized. Second, different from previous studies, we observed not only albuminuria, but also impaired eGFR incidence among those who were free of CKD at baseline. Also, our study has several limitations. First, baseline $25(\mathrm{OH}) \mathrm{D}$ was measured only once, which maybe unstable and fluctuated by related factors. Second, since biomedical tests were only done on a subset of the sample (8 special areas-"The longevity village of China"), there may be some selection bias-imbalance between those included and those not (Additional file 1: Table S1). We compared the baseline 
characteristics between the two groups, those include had higher BMI, SBP, and $25(\mathrm{OH})$ D levels. Third, considering all participants were elderly, the results may not be applicable to adults. Fourth, due to the limitation of field survey, the CLHLS study didn't have information on the treatment with vitamin D (drug treatment or intake of nutrients containing vitamin $\mathrm{D}$ ), vitamin $\mathrm{D}$ related indicators tested by blood biochemical tests (parathyroid hormone or phosphate), other confounding unmeasured factors which might have impact on serum 25(OH)D levels. Further cohort study with wide age and longer follow up years were needed.

\section{Conclusions}

In summary, this study demonstrated there was a strong, independent, linear association between baseline lower 25(OH)D level and CKD (including both albuminuria and impaired GFR) incidence. Given the evidence from basic research, it is tempting to speculate that vitamin D deficiency may present a novel indicator for CKD incidence and progression.

\section{Additional file}

Additional file 1: Table S1. Baseline characteristics of participants included in the analysis and those excluded. (DOC $45 \mathrm{~kb}$ )

\section{Abbreviations \\ ALT: Alanine aminotransferaseBMlbody mass indexCIConfidence intervalCKDChronic kidney diseaseCLHLSChinese Longitudinal Healthy Longevity SurveyDBPDiastolic blood pressureDRDiabetic retinopathyFBGFasting plasma glucoseeGFREstimated glomerular filtrationHDL-CHigh density lipoprotein cholesterolHRHazard ratioLDL-CLow density lipoprotein cholesterolSBPSystolic blood pressureTBiLBilirubinTCTotal cholesterolTGTriglyceride2hPGTwo hours plasma glucose;}

\section{Acknowledgments}

We thank the staff from Center for Healthy Ageing and Development Studies, Peking University for the data from the longitudinal health and Longevity Survey (CLSHL).

\section{Funding}

This study is supported by research grants from This study is supported by research grants from Beijing Nova Program (Z181100006218085), Opening Foundation of State Key Laboratory of Kidney Diseases (KF-01-115), Opening Foundation (NCRCG-PLAGH-2017017), National Natural Science Foundation of China (81703285), Beijing Natural Science Foundation (7174350), Beijing Municipal Science and Technology Commission (Z161100005016021), Military Fund (15BJZ41, 17BJZ51).The views and opinions expressed in this paper are those of the authors and do not necessarily reflect the official position of the study sponsors.

\section{Availability of data and materials}

All data used in this study was stored at Peking university (http:// opendata.pku.edu.cn/) and available upon request.

\section{Authors' contributions}

$\mathrm{ML}$. and $\mathrm{YH}$. contributed to the design of the study. All authors were involved in the analysis and interpretation of the data. JHW. and ML. conducted the statistical analysis. ML. and $\mathrm{YH}$. worked on the drafting of the manuscript, which was thoroughly reviewed and approved by all the authors.

\section{Ethics approval and consent to participate}

The use of CLHLS data was approved by the Biomedical Ethics Committee of Peking University, and written informed consent was obtained from each respondent.

\section{Consent for publication}

Not applicable.

Competing interests

The authors declare that they have no competing interest.

\section{Publisher's Note}

Springer Nature remains neutral with regard to jurisdictional claims in published maps and institutional affiliations.

Received: 28 May 2018 Accepted: 3 January 2019

Published online: 15 January 2019

\section{References}

1. Adams JS, Hewison M. Update in vitamin D. J Clin Endocrinol Metab. 2013; 95(2):471.

2. Ekmekcioglu C, Haluza D, Kundi M. 25-Hydroxyvitamin D status and risk for colorectal Cancer and type 2 diabetes mellitus: a systematic review and meta-analysis of epidemiological studies. Int J Environ Res Public Health. 2017;14(2):127.

3. Bertone-Johnson ER, Chen WY, Holick MF, Hollis BW, Colditz GA, Willett WC, et al. Plasma 25-hydroxyvitamin D and 1,25-dihydroxyvitamin D and risk of breast cancer. Cancer epidemiology, biomarkers \& prevention : a publication of the American Association for Cancer Research, cosponsored by the American Society of Preventive Oncology. 2005;14(8):1991.

4. Damasiewicz MJ, Magliano DJ, Daly RM, Gagnon C, Zhong XL, Ebeling PR, et al. 25-hydroxyvitamin D levels and chronic kidney disease in the AusDiab (Australian diabetes, obesity and lifestyle) study. BMC Nephrol. 2012;13(1):55.

5. Elfakhri N, Mcdevitt H, Shaikh MG, Halsey C, Ahmed SF. Vitamin D and its effects on glucose homeostasis, cardiovascular function and immune function. Horm Res Paediatr. 2014;81(6):363-78.

6. Artaza JN, Sirad F, Ferrini MG, Norris KC. 1,25(OH)2 vitamin D3 inhibits cell proliferation by promoting cell cycle arrest without inducing apoptosis and modifies cell morphology of mesenchymal multipotent cells. J Steroid Biochem Mol Biol. 2010;119(1-2):73.

7. Yano Y, Fujimoto S, Asahi K, Watanabe T. Prevalence of chronic kidney disease in China. Lancet. 2012;380(9838):815-22.

8. Coresh J, Astor BC, Greene T, Eknoyan G, Levey AS. Prevalence of chronic kidney disease and decreased kidney function in the adult US population: third National Health and nutrition examination survey. Am J Kidney Dis. 2003;41(1):1-12.

9. Wang S, Chen R, Liu Q, Shu Z, Zhan S, Li L. Prevalence, awareness and treatment of chronic kidney disease among middle-aged and elderly: the China health and retirement longitudinal study. Nephrology. 2015;20(7):474-84.

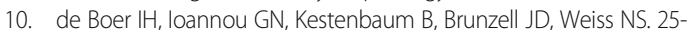
Hydroxyvitamin D levels and albuminuria in the third National Health and nutrition examination survey (NHANES III). Am J Kidney Dis. 2007;50(1):69-77.

11. González EA, Sachdeva A, Oliver DA, Martin KJ. Vitamin D insufficiency and deficiency in chronic kidney disease. Am J Nephrol. 2004;24(5):503-10.

12. Mckibben RA, Zhao D, Lutsey PL, Schneider AL, Guallar E, Mosley TH, Michos ED. Factors associated with change in 25-hydroxyvitamin D levels over longitudinal followup in the ARIC study. J Clin Endocrinol Metab. 2016;101(1):33-43.

13. Boer IHD, Katz R, Chonchol M, Ix JH, Sarnak MJ, Shlipak MG, et al. Serum 25Hydroxyvitamin D and change in estimated glomerular filtration rate. Clinical Journal of the American Society of Nephrology Cjasn. 2141;6(9):2011.

14. Zeng Y. Chinese longitudinal healthy longevity survey(1998-2012) and related policy research review. Scientific Research on Aging. 2013.

15. Holick MF, Binkley NC, Bischoffferrari HA, Gordon CM, Hanley DA, Heaney RP, et al. Evaluation, treatment, and prevention of vitamin D deficiency: an Endocrine Society clinical practice guideline. J Clin Endocrinol Metab. 2011;96(7):1911.

16. Liao Y, Liao W, Liu J, Xu G, Zeng R. Assessment of the CKD-EPI equation to estimate glomerular filtration rate in adults from a Chinese CKD population. J Int Med Res. 2011;39(6):2273.

17. Isakova T, Gutiérrez OM, Patel NM, Andress DL, Wolf M, Levin A. Vitamin D deficiency, inflammation, and albuminuria in chronic kidney disease: complex interactions. J Ren Nutr. 2011;21(4):295-302. 
18. Ravani P, Malberti F, Tripepi G, Pecchini P, Cutrupi S, Pizzini P, et al. Vitamin D levels and patient outcome in chronic kidney disease. Kidney Int. 2009; 75(1):88-95,

19. Reynolds BS, Lefebvre HP. Feline CKD: Pathophysiology and risk factors-what do we know? Journal of Feline Medicine \& Surgery 2013;15 Suppl 1(S1):3.

20. Andress DL. Vitamin $D$ in chronic kidney disease: a systemic role for selective vitamin D receptor activation. Kidney Int. 2006;69(1):33-43.

21. Szeto CC, Li KT. The use of vitamin $D$ analogues in chronic kidney diseases: possible mechanisms beyond bone and mineral metabolism. Ndt Plus. 2009:2(3):205-12.

22. Brown JM, Secinaro K, Williams JS, Vaidya A. Evaluating hormonal mechanisms of vitamin $D$ receptor agonist therapy in diabetic kidney disease: the VALIDATE-D study. BMC Endocr Disord. 2013;13(1):33.

Ready to submit your research? Choose BMC and benefit from:

- fast, convenient online submission

- thorough peer review by experienced researchers in your field

- rapid publication on acceptance

- support for research data, including large and complex data types

- gold Open Access which fosters wider collaboration and increased citations

- maximum visibility for your research: over $100 \mathrm{M}$ website views per year

At BMC, research is always in progress.

Learn more biomedcentral.com/submissions 